\title{
Construction Control Room for Project Monitoring and Control
}

\author{
Ali Ezzeddine $^{1}$, Lynn Shehab ${ }^{1}$, Issam Srour ${ }^{1}$ and William Power ${ }^{2}$
}

1 American University of Beirut, Beirut, Lebanon

2 DPS Group, Little Island, Co. Cork, Ireland

\begin{abstract}
The world is a dynamic and ever-changing environment leading decision makers to believe that from plan to execution, unforeseen conditions will undoubtedly occur. The military is known to face unforeseen obstacles while conducting the operations forcing leaders to plan deviations. The construction sector is not far from the military in terms of planning and executing under uncertainty. One common problem the sector faces is delay in completing tasks and, consequently, projects. To mitigate the effects of uncertainty during operations, the military uses control rooms in order to deal with the worst when it occurs. Military control rooms provide a comfortable and collaborative environment for teams to proactively anticipate, highlight and mitigate potential plan deviations and to resolve emerging problems and constraints fast and efficiently. This paper introduces the concept of military operation rooms to construction by proposing a technology-based Construction Control Room (CCR) where several commercially available technologies are integrated into one comprehensive and inclusive framework for monitoring and controlling ongoing construction activities. It is a collaborative space where all relevant design and construction entities are present. Site data and requests are received, monitored, and processed directly in the control room for proactive and corrective measures. Moreover, this paper presents the elements of a simulation-based tool which outputs the required number of personnel in the CCR. Real project data is obtained from a live project that one of the authors worked on in Western Europe. Data is used to build a discrete-event simulation model that mimics the workflow in the real system in order to analyze the flow of information within the room, suggest the optimum number of members that should be present in each entity, and monitor the resource utilization of each entity. The results of the model show the potential of using such control rooms for enhancing construction project delivery.
\end{abstract}

(c) 2020 The Authors. Published by Budapest University of Technology and Economics \& Diamond Congress Ltd Peer-review under responsibility of the Scientific Committee of the Creative Construction Conference 2020.

Keywords: construction control room, discrete-event simulation, technology, lean construction

\section{Introduction}

The world as we know it is a dynamic and ever-changing environment. Decision makers believe that between the plan and execution, unforeseen conditions will undoubtedly occur [1]. In the word of military operations, every step within the plan is susceptible to change. Helmuth von Moltke (1871), Head of the Prussian \& German Staff, explains, "No plan of operations extends with certainty beyond the first encounter with the enemy's main strength. Only the layman sees in the course of a campaign a consistent execution of preconceived and highly detailed original concept pursued consistently to the end". The construction industry is akin to the military in terms of planning and execution uncertainty. One of the most common issues construction faces is project and task delays [2]. Planners also face uncertainties on a regular basis throughout the project's lifecycle. Researchers have found that more than $56 \%$ of construction projects suffer from uncertainties [3]. Additionally, uncertainties affect not only project objectives and means, but also impact production systems in terms of workflow and resource availability [4]. 
To mitigate the effects of uncertainty during operations, the military uses control rooms in order to stay on alert to proactively detect any unforeseen enemy ambushes and to deal with the worst when it occurs. Military control rooms provide a comfortable and collaborative environment for teams to resolve emerging problems and constraints in a fast and efficient way. Several economic and trade sectors have adopted control rooms to monitor and control their tasks such as in nuclear power plants [5].

In construction, several technologies are being developed to enhance the planning and control aspects of projects [6]. Li et al. 2015 used game engines to develop a tool that visualizes the location of workers wearing location tracking devices during pre-cast concrete installation to proactively detect any unsafe behavior [7]. Moreover, several frameworks and tools have been developed for visual planning and monitoring in construction. The closest concept to the military control room in construction has been introduced for the purpose of visualizing the progress during meetings. A computer application has been used to display current project data and compare different scenarios during team meetings [8]. Furthermore, Virtual Reality (VR) technology is also being used to create a collaborative VR environment. An immersive VR-Based collaborative environment enhances the experience and efficiency of constructability related meetings [9]. Another framework has been proposed to allow engineers to visually inspect and analyze project data and the interdependencies between building elements [10]. McHugh et al. 2019 integrated the famous lean construction system, The Last Planner System (LPS) for Production Control with Building Information Modeling (BIM). The research presented a case study in which the researchers implemented this integration using a tool named VisiLean. VisiLean allows planners to develop look-ahead and weekly plans in a digitized system which is directly visualized in the BIM model rather than the traditional sticky note method. In the presented case study, the proposed system was implemented in a meeting room having digitized walls to screen the system [11]. Although researchers have developed many tools to enhance project collaboration and project control, little effort has been made to develop a concept similar to that of the military control room. Perhaps, the system presented by McHugh et al. 2019 is the closest in concept to the military control room. However, the presented system is mostly used during meetings and planning sessions rather than on-going $24 / 7$ monitoring and control.

This paper aims to add to the previously developed concepts in construction management to enhance project monitoring and control by presenting the Construction Control Room (CCR). It presents the concept of a technology-based control room to proactively and continuously monitor on-going projects and detect any deviations from the plan. Several technologies are used to connect the flow of information from the site to the CCR, and integrate them into one comprehensive and inclusive framework for project monitoring and control. A simulation model is developed to simulate and analyze the workflow within the control room showing the collaboration of different entities present in a construction project. Moreover, various technologies and tools that can be used within the control room are discussed, such as: (1) Obtaining live feed from the actual project construction site through Unmanned Aerial Vehicles (UAVs) and static cameras in order to stay updated with the progress, faced constraints, delays etc., (2) using Building Information Modeling (BIM) to track the progress of the project and to obtain updated models of the actual project, and (3) incorporating the Metrics Prediction Tool developed earlier by the authors [12,13] into the proposed control room. The tool is fed inputs directly from the site and gives metrics that are crucial for project monitoring and progress prediction. Moreover, the tool allows for better activity progress monitoring at the weekly work plan level by detecting clashes, delays, area congestions, in addition to predicting important metrics such as the PPC and a newly developed Percent Improved Complete (PIC).

\section{Literature review}

In this section, we will go over topics related to the idea of this paper. First, the implementations of control rooms in various industries will be discussed. To the best of our knowledge, no simulation model has been built to mimic and study the significance of using control rooms in construction. Hence, simulation will be explained and discussed to introduce it as part of the methodology of this paper. Finally, we will go over the major philosophies, tools, and techniques of Lean construction which is the theme of the proposed CCR. 


\subsection{Control rooms}

Due to the complex and unpredictable nature of military operations, commanders and generals need a system to keep an eye on critical ongoing operations; this is the military control room or operation control center. This concept is recognizable from military-themed movies. These rooms have two main elements; a collaborative workspace and technological support. The control room allows commanders, generals, and all relevant personnel to be working together in a shared physical room. These rooms are equipped with all necessary technologies to support the flow of information and live feedback from the location the operation is being conducted in, to the control room. The control room allows its users to focus on missions, communicate effectively with other members of the command, operational teams, and support groups, and work collaboratively in an organized and comfortable environment.

Due to the aforementioned advantages of control rooms, several different industries have adopted such systems to enhance their processes. Electric power plants use control rooms to monitor electric supply grids and to communicate with field and generation operators [14]. Nuclear power plants also use control rooms to monitor and control operations, processes, and any deviations in the process state. Their control rooms use alarm systems, diagnostic systems, and cameras to allow for better monitoring [15]. All airports also have control rooms that use radar technology to monitor and plan airplanes' arrivals, departures, and takeoffs [16]. To monitor roads and highways, transportation control centers are equipped with large screens that acquire live video feed from city roads. These control centers are used to monitor traffic intersections and any accidents that might occur on the roads [17].

In construction, Fischer et al. [8] developed a tool called CIFE iRoom that integrates several project information and documents such as CPM and 4D schedules. The information is presented and visualized on three large screens so that all entities in the room can have visual access to the presented information [18]. In Lean Construction, a similar computer-aided system named VisiLean is developed which focused on enhancing planning sessions within the Last Planner System. VisiLean is used to perform phase, lookahead, and weekly planning in a technological framework. The main goal behind developing this system is to integrate the production planning of lean construction with BIM. Planners are able to place virtual sticky notes during planning sessions onto building elements within the BIM model [19]. A research study has shown that using VisiLean in collaborative rooms similar the CCR presented in this paper, can reduce defects and labor cost, and improve program efficiency [11]. To the best of our knowledge, no simulation model has been built to mimic and study the significance of control rooms in construction.

\subsection{Simulation}

Simulation as defined by Shannon [20] is the process of building and experimenting with a computerized model of a system to understand its behavior or to evaluate different operation strategies. The use of simulation was first introduced to construction by Teicholz in 1963 [21]. In construction, simulation can enhance our understanding of the processes, and allows us to perform different types of experiments to lower costs and optimize schedules [21]. Several simulation software have been developed including Cyclone, EZSTROBE, and STROBOSCOPE [22].

There are several types of simulation. System Dynamics (SD) is suitable for strategic decision-making or policy analysis [23]. Discrete-Event Simulation (DES) is a process-centric simulation where a chain of activities linked together through certain conditions and resources are represented. DES models are dynamic, as time is a significant factor where only discrete points of time are considered, such as the time of occurrence of an event [24]. Another type of simulation is Agent-Based Modelling and Simulation (ABMS), which is defined by agents and the environment in which they exist. The behavior of the agents and their interactions among themselves and with their environment are described by certain rules that are defined in the model. ABMS's ability to model complex systems has enabled it to become one of the most popular simulation techniques.

The process of building a simulation model begins with setting the goals and objectives of the model. Developed ideas can then be translated into simulation terminologies where important parameters, resources, and relations are defined. Since real systems are extremely complex, simulation models 
sometimes assume or neglect some factors for simplicity purposes. After a model is built, verification and validation must be performed. Verification is checking if the model is built right, while validation is checking if the right model is built. In the former, the model's scope, inputs, and performance are checked in compliance with the initial concepts and expectations. In the latter, the model's execution and output are checked to be in harmony with the real world's behavior [24]. In construction, simulation techniques are being used in numerous settings for decision making on construction projects [21].

\subsection{Lean construction}

The goals of lean thinking redefine performance based on three aspects: a uniquely custom product, instant delivery, and zero inventory [25]. "Creating Value for the Customer with no waste" [26] succinctly defines Lean production; with waste being defined as anything that does not add Value to, and in the eyes of, the customer. It is suggested Lean thinking can provide the basis for improving the efficiency of the construction sector and significantly increase its value-offering. Lean construction is a relatively new approach to managing construction [25]. It emerged in the mid-1990s [27] focusing on two aspects. The first is time, money, and equipment waste reduction, while the second is managing flows [28].

Several lean tools and techniques have been introduced to the industry including the Kanban system, which is a Japanese word meaning card or sign board. In the Toyota Production System (or Lean Production), cards are used to control materials flow through the factory by only requesting components delivery from a supplier when they are needed [27]. Another tool is the Obeya system or "big room". It is similar to a control room where a group of experts are gathered to review the progress of the program and discuss key decisions [29]. Toyota identified 14 main principles to establish a lean process within a production system. One of these principles is "Use Visual Control so No Problems Are Hidden". Construction is starting to adopt this principal through dashboards which clearly visualize important project metrics and data. Researchers are developing guidelines to follow while developing construction dashboards. For example, the dashboard should fit to one screen, and vibrant colors should be used to grab the users' attention to important values or messages [30].

\section{Methodology}

This study adopts Design Science Research (DSR) as the main research methodology. DSR produces scientific knowledge as opposed to explanatory research that aims to understand and predict phenomena in a certain field [31]. It also connects research and practice leading to stronger relevance of academic construction management [32]. This paper aims to link research (technological advancements in construction) with practice (a practical framework for project monitoring and control) by designing a control room that integrates different technologies into one framework. The construction control room is inspired by military operations rooms where different entities work together collaboratively in an open space. Site data and requests are received, monitored, and processed directly in the control room for proactive and corrective measures. The control room integrates several construction technologies and uses real project data to build a discrete-event simulation model that mimics the workflow in the real system.

\section{Architecture of the construction control room}

As mentioned earlier, the construction control room coordinates, supervises, and controls all ongoing live construction activities. Hence, it combines all relevant design and construction entities. The project commander (Construction Manager or Superintendent) is the highest authority in the control room whose job is to facilitate the flow of information within the room. The room includes entities such as construction managers, architects, and engineers from all disciplines as shown in Figures 1 and 2. 


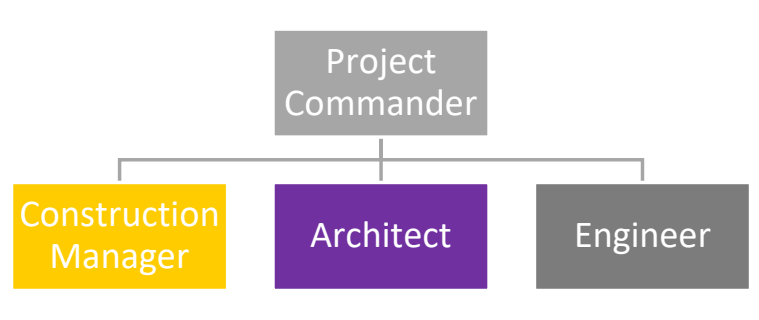

Figure 1. Personnel Hierarchy

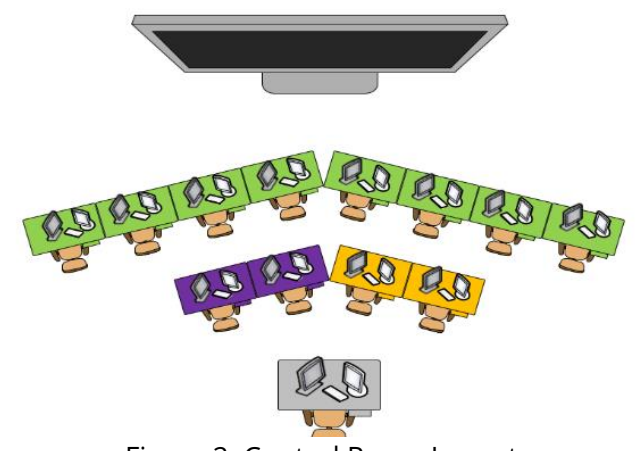

Figure 2. Control Room Layout

Lean construction posits integrating several project entities into one collaborative room, also known as Obeya Room where progress is monitored, and decisions are made collaboratively. In the control room, large screens can be used to monitor several streams of incoming live data in order to facilitate data analysis and data-based rapid decision making. Several technologies can be used to obtain project data and monitor its progress. Some of the suggested technologies are discussed next.

\subsection{Unmanned Aerial Vehicles (UAVs)}

UAVs are aerial vehicles that can fly autonomously or via human remote control without the need for onboard human assistance. The terms UAV and drones refer to the same aerial vehicle in this context. Recently, UAV applications have increased in several industries due to their ease of use and relative affordability, and construction is no exception [33]. UAVs are used to capture images and videos for construction sites to build an as-built 3D model. The models are then compared to the BIM models to assess construction progress [34]. Moreover, drones equipped with laser scanners are able to estimate the volumes of soil excavations quickly and more accurately than traditional human surveying methods [35]. In logistics management, drones are used to track materials on-site using GPS and ultra-wide band radio frequencies. Drones are also used to check for structural failures and defects in concrete bridges [36]. Coifman et al. 2004 used drones for transportation surveillance on highways and road intersections and numerous researchers have investigated the applicability of drones for safety inspections on construction sites [37].

\subsection{Trello}

Trello is a cloud-based and Kanban-style project management tool that aids users in managing and organizing their tasks. Trello uses a wide virtual board on which users can see all activities and information. Users only require internet access to view the content on the project's board, and those who wish to add content to the board are required to have an account on Trello [38].

\subsection{Location Based Management System (LBMS)}

Location-based schedules are linear schedules that show the progress of tasks within the working locations [39]. LBMS is mostly known for visually managing buffers between tasks, achieving continuity in workflow, monitoring task progress, forecasting task progress, and warning about cascading delays [40]. LBMS aids the process of project control, as the sequence of control in LBMS is monitoring progress, forecasting, and identifying and solving problems [41]. Hence, using LBMS in the CCR to monitor task progress is recommended due to its highly efficient visual techniques. 


\section{Testing CCR on a real-world case study}

To build a DES model, data was obtained from two sources. Regarding the delay times per entity, Mohamed et al. 1999 [42] found that the construction manager needs 3.52 hours to resolve and issue, while architects and engineers need 3.72 hours (Figure 3).

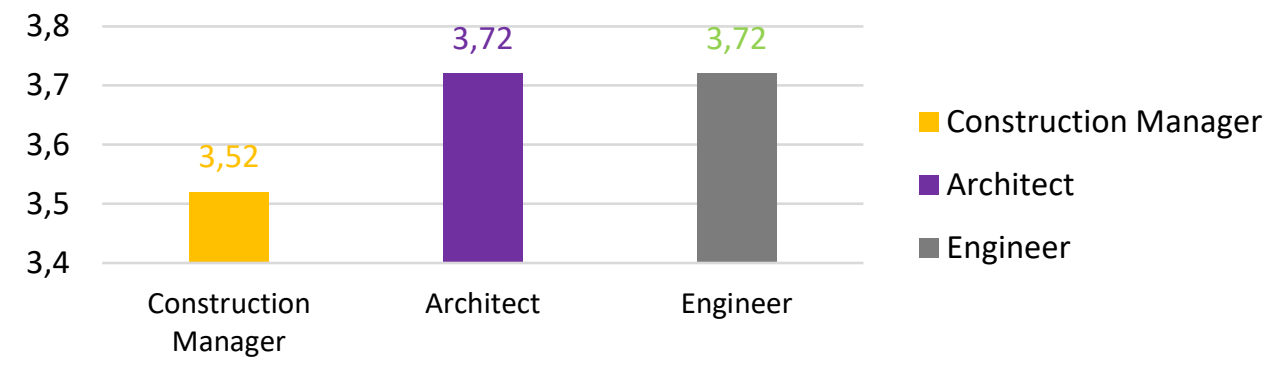

Figure 3. - Delay Times per Entity

Reasons for non-completion of certain construction activities were obtained from a leading Global Project Management And Engineering Company, while delay times per entity were obtained from a research paper by [42]. The reasons for non-completion of planned tasks were recorded for 94 weeks. Afterwards, each reason was attributed to a project entity in charge of addressing the issue (Table 1), and the percentages per entity were as follows: the construction manager was responsible to resolve $67 \%$ of the requests for information (RFIs), the architect was responsible for $17 \%$, and the engineer was responsible for $16 \%$ (Figure 4).

Table 4. Reasons for Non-Completion of Construction Activities and Their Responsible Entities

\begin{tabular}{lccc}
\hline & CM & Architect & Engineer \\
\hline Scope of Work & & $\checkmark$ & \\
Client-Driven Changes/Delays & & $\checkmark$ & $\checkmark$ \\
Arch/Eng/Design RFI & & $\checkmark$ & $\checkmark$ \\
Schedule/Coordination & $\checkmark$ & & \\
Prerequisite Work - Self & $\checkmark$ & & \\
Qualified Staff Availability & $\checkmark$ & & \\
Materials/Suppliers Availability & $\checkmark$ & & \\
Site Conditions & & & $\checkmark$ \\
Incorrect Time Estimates & $\checkmark$ & & \\
Safety Non-Conformance & $\checkmark$ & & \\
Cost/Commercial Prerequisite & $\checkmark$ & & \\
Total Number of Reasons & 2604 & 636 & 633 \\
Percentage & $67 \%$ & $17 \%$ & $16 \%$ \\
\hline
\end{tabular}

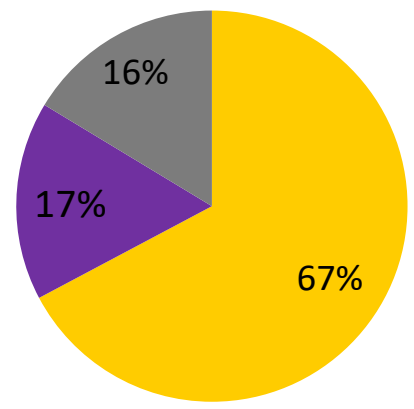

$\square \mathrm{Cm} \square$ Arch $\square$ Eng

Figure 4. - Percentages of Responsibility per Entity

\section{Information flow analysis by Discrete-Event-Simulation}

Discrete-Event Simulation (DES) is used in this paper to represent the workflow within the CCR and to model the process of data transfer between the entities present in the room. The data collected and monitored from the site through the aforementioned technologies is transferred to the control room and consequently to each concerned entity in the room. The time taken for constraints to be removed and RFIs to be dealt with can be one of the indicators for the efficiency of the model.

In the model shown below (Figure 5), site data is collected by drones, LBMS, BIM, and Trello, and are automatically sent to the Commander who is the highest authority in this CCR. He then distributes the data 
to the responsible entities according to the obtained percentages (67\% to the $\mathrm{CM}, 17 \%$ to the $\mathrm{Arch}, 16 \%$ to the Eng). Once the Construction Manager (CM) receives the RFI, he resolves it and sends it back to the commander for approval. If the commander approves it, it is considered resolved. If he disapproves it, it is sent back to the CM for re-resolving. As for the architects and engineers: once they receive an RFI, they resolve it and send it to each other and to the $\mathrm{CM}$ (not the commander). The addressed RFIs are then either approved or rejected by the $\mathrm{CM}$, leading to a wasteful cycle of iteration requiring further attention.

Figure 6 offers a simpler representation. The commander first sends the RFIs to construction manager, architects, and engineers. The CM resolves the RFI and sends it back to the commander for approval. Architects and engineers resolve the RFI and send it (1) to each other and (2) to the CM for approval.

In the first run, a configuration of one commander, one construction manager, one architect, and one engineer was modeled. From the simulation run, delay times per entity and resource utilization (RU) values were obtained. The results of the first iteration are unsatisfactory. The delay time of the CM is too long (378 hours) and the resource utilization is too high. High RU values are physically and mentally draining for entities and lead to fatigue and exhaustion. Several iterations of different configurations (increasing the number of CMs, architects, and engineers) were modeled to reach a balance between delay times and resource utilizations. RU must not be too high, and delay times must be close to those suggested by Mohamad et al. in companies that use web-based management systems (WBMS).

According to the simulation runs, the best configuration for this particular project data is one commander, four CMs, two architects, and two engineers (Figure 7). This configuration gives acceptable delay times that are close to the ones suggested by Mohamed et al. 1999 [42] and average RU values.

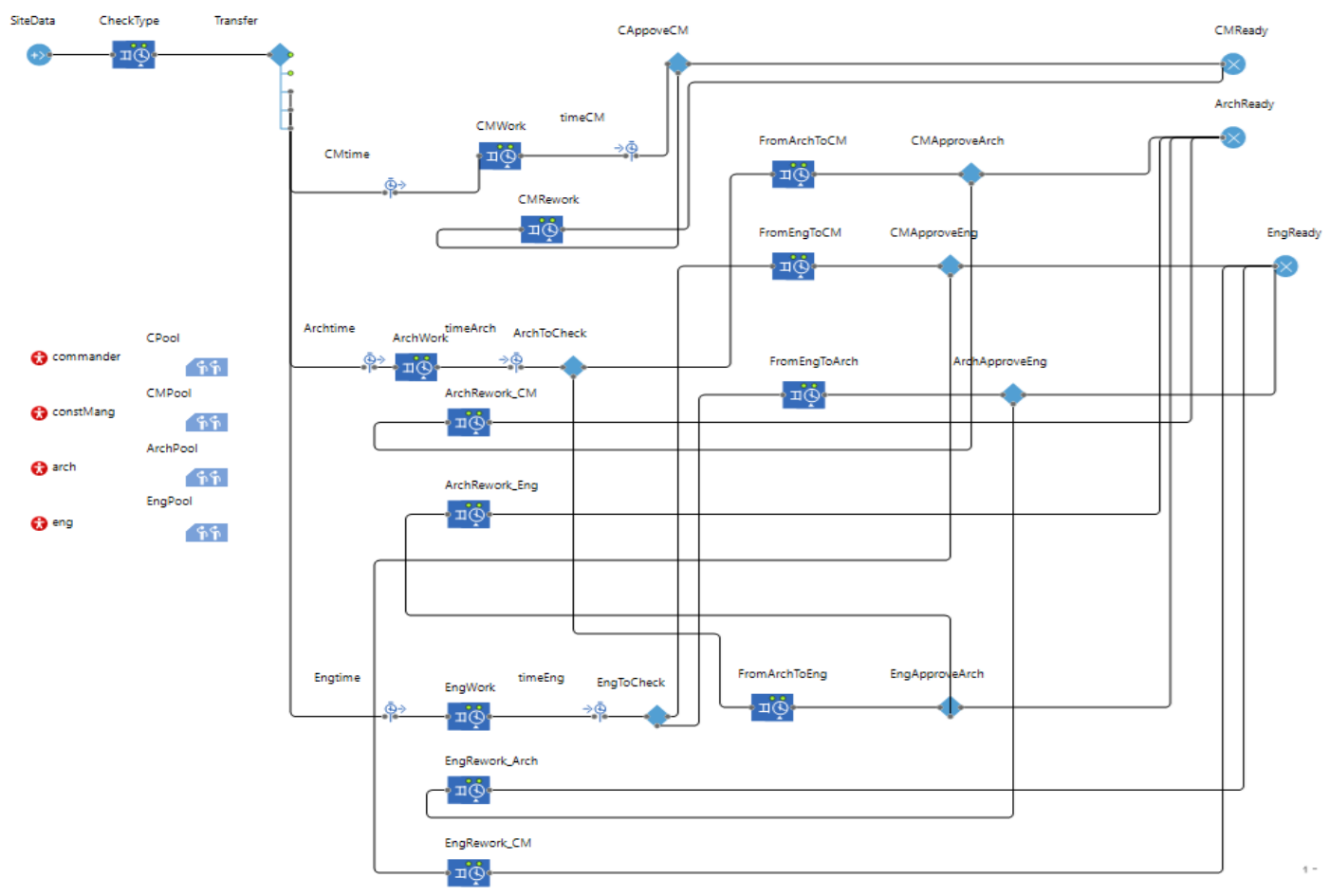

Figure 5. DES Model 


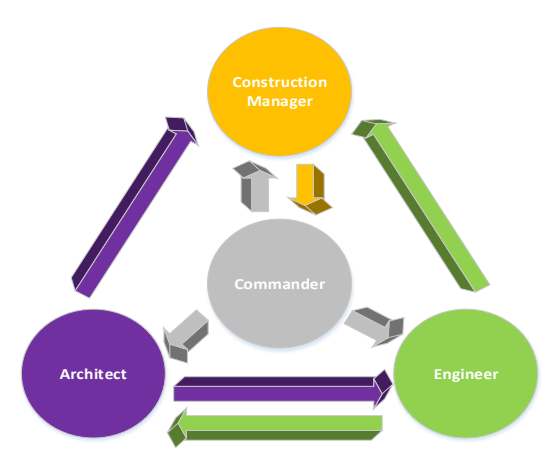

Figure 6. Entity Relationships

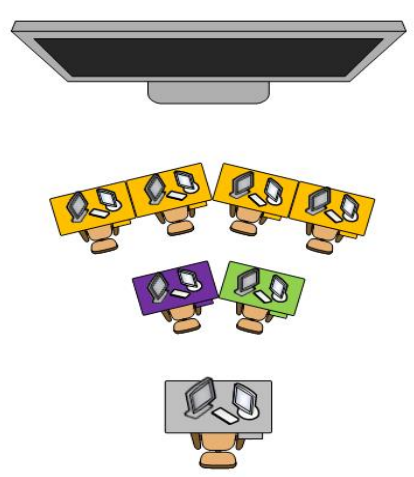

Figure 7. New CCR Configuration

Table 5. Different Simulation Runs with Different Configurations

\begin{tabular}{|c|c|c|c|c|c|c|c|c|c|c|c|}
\hline $\begin{array}{l}\text { Trial } \\
\#\end{array}$ & Commander & $\begin{array}{l}\# \text { of } \\
\mathrm{CM}\end{array}$ & $\begin{array}{l}\# \text { of } \\
\text { Arch }\end{array}$ & $\begin{array}{l}\text { \# of } \\
\text { Eng }\end{array}$ & $\begin{array}{l}\text { CM Duration } \\
\text { (hr) }\end{array}$ & $\begin{array}{l}\text { Arch } \\
\text { Duration (hr) }\end{array}$ & $\begin{array}{l}\text { Eng Duration } \\
\text { (hr) }\end{array}$ & $\begin{array}{l}\text { C } \\
\text { Util. }\end{array}$ & $\begin{array}{l}\text { CM } \\
\text { Util. }\end{array}$ & $\begin{array}{l}\text { Arch } \\
\text { Util. }\end{array}$ & $\begin{array}{l}\text { Eng } \\
\text { Util. }\end{array}$ \\
\hline 1 & 1 & 1 & 1 & 1 & 378.89 & 4.88 & 5.08 & $69 \%$ & $100 \%$ & $44 \%$ & $43 \%$ \\
\hline 2 & 1 & 2 & 1 & 1 & 11.54 & 6.01 & 5.61 & $47 \%$ & $90 \%$ & $57 \%$ & $60 \%$ \\
\hline 3 & 1 & 3 & 1 & 1 & 4.23 & 5.54 & 5.89 & $47 \%$ & $62 \%$ & $59 \%$ & $61 \%$ \\
\hline 4 & 1 & 6 & 1 & 1 & 3.52 & 5.81 & 5.32 & $47 \%$ & $33 \%$ & $54 \%$ & $52 \%$ \\
\hline 5 & 1 & 6 & 4 & 4 & 3.51 & 3.53 & 3.45 & $47 \%$ & $32 \%$ & $14 \%$ & $14 \%$ \\
\hline 6 & 1 & 5 & 3 & 3 & 3.56 & 3.61 & 3.52 & $47 \%$ & $38 \%$ & $19 \%$ & $18 \%$ \\
\hline 7 & 1 & 4 & 2 & 2 & 3.65 & 3.66 & 3.67 & $47 \%$ & $50 \%$ & $26 \%$ & $29 \%$ \\
\hline 8 & 1 & 4 & 1 & 1 & 3.66 & 5.17 & 5.45 & $48 \%$ & $48 \%$ & $57 \%$ & $54 \%$ \\
\hline \multicolumn{5}{|c|}{ OPTIMAL [51]: } & 3.52 & 3.72 & 3.72 & & & & \\
\hline
\end{tabular}

\section{Conclusion}

The goal of this paper is to introduce the concept of military operation rooms to construction by proposing a technology-based CCR where several technologies are integrated into one comprehensive and inclusive framework. Such technologies include drones, LBMS, BIM, and Trello. A CCR allows for global collaboration among various project entities, accurate progress monitoring, and proactive issue resolution. While similar concepts such as the war room have been developed and used in the construction industry, no research or application has been found similar to the one presented in this paper. The work suggests that each project should have a CCR that not only is used for meetings but also overlooks all related activities of the project 24/7. Thus, as long as there is a task being executed on site, the CCR will be monitoring and controlling the execution of this task.

DES is used calculate the number of personnel in the CCR and to model the process of data-transfer and RFI resolution among all project entities. It represents the flow of information from the point the information or request reaches the CCR, to the point of resolving the request and sending it to the site. To build the model in an accurate manner, data from a project one of the authors worked on was used. Afterwards, the authors were able to calculate the total number of requests issued per week and the percentage of requests that were sent to either the construction managers, the architects, or the engineers for them to resolve. The simulation model was then used as tool to assist in calculating the optimum number of entities from each department that should be allocated in the CCR. For the project in hand, it was found that there should be one commander, four construction managers, two architects, and two engineers. The model can be used for different projects to calculate the resource allocation of the required CCR. 
Future work will further develop the concept of the CCR. The authors plan to investigate the feasibility and the costs and potential savings of using the CCR. Moreover, further study is required to identify the most suitable individual in the project team to command this CCR or decide if an individual from outside the project's team should host it for an objective, independent, unbiased viewpoint to counter the optimism witnessed in many projects that go over schedule and budget. Finally, future studies will also focus on investigating the most suitable delivery method to use the CCR.

\section{References}

[1] Davidson, P., 1991, "Is Probability Theory Relevant for Uncertainty? A Post Keynesian Perspective," J. Econ. Perspect., 5(1), pp. 129-143. https://doi.org/10.1257/jep.5.1.129

[2] Assaf, S. A., and Al-Hejji, S., 2006, "Causes of Delay in Large Construction Projects," Int. J. Proj. Manag., 24(4), pp. $349-357$. https://doi.org/10.1061/(ASCE)0742-597X(1995)11:2(45)

[3] Howell, G., Laufer, A., and Ballard, G., 1993, “Uncertainty and Project Objectives,” Proj. Apprais., 8(1), pp. 37-43. https://doi.org/10.1080/02688867.1993.9726884

[4] Ballard, G., and Howell, G., 1998, "Shielding Production: Essential Step in Production Control,” J. Constr. Eng. Manag., 124(1), pp. 11-17. https://doi.org/10.1061/(ASCE)0733-9364(1998)124:1(11)

[5] Harmon, D. L., Jamison, D. S., and Scarola, K., 1994, "Compact Work Station Control Room," p. 18.

[6] Song, L., and Eldin, N. N., 2012, "Adaptive Real-Time Tracking and Simulation of Heavy Construction Operations for Look-Ahead Scheduling," Autom. Constr., 27, pp. 32-39. https://doi.org/10.1016/j.autcon.2012.05.007

[7] Li, H., Lu, M., Chan, G., and Skitmore, M., 2015, "Proactive Training System for Safe and Efficient Precast Installation," Autom. Constr., 49, pp. 163-174. https://doi.org/10.1016/j.autcon.2014.10.010

[8] Fischer, M., Stone, M., Liston, K., Kunz, J., and Singhal, V., 2002, "Multi-Stakeholder Collaboration: The CIFE IRoom," Proceedings CIB W78 Conference, pp. 6-13.

[9] Boton, C., 2018, "Supporting Constructability Analysis Meetings with Immersive Virtual Reality-Based Collaborative BIM 4D Simulation," Autom. Constr., 96, pp. 1-15. https://doi.org/10.1016/j.autcon.2018.08.020

[10] Kuo, C. H., Tsai, M. H., and Kang, S. C., 2011, "A Framework of Information Visualization for Multi-System Construction," Autom. Constr., 20(3), pp. 247-262. https://doi.org/10.1016/j.autcon.2010.10.003

[11] McHugh, K., Dave, B., and Craig, R., 2019, "Integrated Lean and Bim Processes for Modularised Construction - A Case Study," Proc. 27th Annu. Conf. Int. Gr. Lean Constr., pp. 228-238. https://doi.org/10.24928/2019/0252

[12] Ezzeddine, A., Shehab, L., Hamzeh, F., and Lucko, G., 2019, "Singularity Functions to Enhance Monitoring in the Last Planner System," 27th Annual Conference of the International Group for Lean Construction, International Group for Lean Construction (IGLC), Dublin, Ireland, pp. 287-298. https://doi.org/10.24928/2019/0134

[13] Shehab, L. G., Ezzeddine, A. M., Hamzeh, F. R., and Lucko, G., 2019, "Singularity Functions for Early Warning Guidance in the Last Planner System®," Lean Constr. J., 2019, pp. 76-90.

[14] Obradovich, J. H., 2011, "Understanding Cognitive and Collaborative Work: Observations in an Electric Transmission Operations Control Center," Proc. Hum. Factors Ergon. Soc., pp. 247-251. https://doi.org/10.1177/1071181311551051

[15] Hogg, D. N., Follesø, K., Strand-Volden, F., and Torralba, B., 1995, "Development of a Situation Awareness Measure to Evaluate Advanced Alarm Systems in Nuclear Power Plant Control Rooms," Ergonomics, 38(11), pp. 2394-2413. https://doi.org/10.1080/00140139508925275

[16] Hurst, M. W., and Rose, R. M., 1978, "Objective Workload and Behavioural Response in Airport Radar Control Rooms," Ergonomics, 21(7), pp. 559-565. https://doi.org/10.1080/00140137808931755

[17] Monahan, T., 2007, “'War Rooms' of the Street: Surveillance Practices in Transportation Control Centers," Commun. Rev., 10(4), pp. 367-389. https://doi.org/10.1080/10714420701715456

[18] Schreyer, M., Hartmann, T., and Fischer, M., 2005, "Supporting Project Meetings with Concurrent Interoperability in a Construction Information Workspace," Electron. J. Inf. Technol. Constr., 10(August 2004), pp. 153-167.

[19] Dave, B., and Koskela, L. J., 2011, "Visilean: Designing a Production Management System with Lean and BIM," International Group for Lean Construction.

[20] Shannon, R. E., 1975, "Simulation: A Survey with Research Suggestions," AllE Trans., 8(1), pp. 289-296. https://doi.org/10.1080/05695557508975010

[21] AbouRizk, S., 2010, "Role of Simulation in Construction Engineering and Management," J. Constr. Eng. Manag., 136(10), pp. 11401153. https://doi.org/10.1061/(ASCE)CO.1943-7862.0000220

[22] Halpin, D., 1977, "CYCLONE: Method for Modeling of Job Site Processes," J. Constr. Div., 103(3), pp. 489-499.

[23] Sterman, J. D., 2000, Business Dynamics: Systems Thinking and Modeling for a Complex World, Boston, MA: Irwin/McGraw-Hill.

[24] Abou-lbrahim, H., Zankoul, E., Hamzeh, F., and Rizk, L., 2019, "Understanding the Planner's Role in Lookahead Construction Planning," Prod. Plan. Control, 30(4), pp. 271-284. https://doi.org/10.1080/09537287.2018.1524163

[25] Howell, G., and Ballard, G., 2010, "Implementing Lean Construction," Lean Constr., (May), pp. 111-126. https://doi.org/10.4324/9780203345825 Implementing lean construction

[26] Oakland, J., and Marosszeky, M., 2017, Total Construction Management: Lean Quality in Construction Project Delivery, Routledge. https://doi.org/10.4324/9781315694351

[27] Koskela, L., Howell, G., Ballard, G., and Tommelein, I., 2002, “The Foundations of Lean Construction,” Des. Constr. Build. Value, 291, pp. 211-226.

[28] Ballard, G., and Howell, G., 1994, "Implementing Lean Construction: Stabilizing Work Flow," Lean Constr., 2, pp. $105-114$.

[29] Liker, J. K., 2004, The Toyota Way - 14 Management Principles from the World's Greatest Manufacturer, McGraw Hill, NY.

[30] Velcu, O., and Yigitbasioglu, O., 2012, "A Review of Dashboards in Performance Management: Implications for Design and Research," Int. J. Account. Inf. Syst., 13(1), pp. 41-59.

[31] Rocha, C. G., Formoso, C. T., and Tzortzopoulos-fazenda, P., 2012, "Design Science Research in Lean Construction: Process and Outcomes," Proceedings for the 20th Annual Conference of the International Group for Lean Construction.

[32] Alsehaimi, A., Koskela, L., and Tzortzopoulos, P., 2013, "Need for Alternative Research Approaches in Construction Management: Case of Delay Studies," J. Manag. Eng., 29(4), pp. 407-413. https://doi.org/10.1061/(ASCE)ME.1943-5479.0000148 
[33] Tatum, M. C., and Liu, J., 2017, "Unmanned Aerial Vehicles in the Construction Industry," Anual International Conference Proceedings, pp. 383-393.

[34] Anwar, N., Amir, M., and Ahmed, F., 2018, "Construction Monitoring and Reporting Using Drones and Unmanned Aerial Construction Monitoring and Reporting Using Drones and Unmanned Aerial Vehicles ( UAVs )," Tenth Int. Conf. Constr. 21st Century, (July)

[35] Devers, W., 2018, "A Case Study on the Use of Drones on Heavy Civil Construction Projects."

[36] Li, Y., and Liu, C., 2019, "Applications of Multirotor Drone Technologies in Construction Management," Int. J. Constr. Manag., 19(5), pp. 401-412. https://doi.org/10.1080/15623599.2018.1452101

[37] Coifman, B., McCord, M., Mishalani, R. G., and Redmill, K., 2004, "Surface Transportation Surveillance from Unmanned Aerial Vehicles," Proc. 83rd Annu. Meet. Transp. Res. Board.

[38] Johnson, MLIS, H. A., 2017, "Trello," J. Med. Libr. Assoc., 105(2), pp. 2016-2018.

[39] Kenley, R., and Seppänen, O., 2010, Location-Based Management for Construction, Routledge.

[40] Seppänen, O., 2013, "A Comparison of Takt Time and LBMS Planning Methods," Int. Gr. Lean Constr., pp. 727-738.

[41] Heinonen, A., and Seppänen, O., 2016, "Takt Time Planning in Cruise Ship Cabin Refurbishment: Lessons for Lean Construction," Annual Conference of the International Group for Lean Contruction IGLC, pp. 23-32.

[42] Mohamed, S., Tilley, P. ., and Tucker, S. ., 1999, "Quantifying The Time And Cost Associated With The Request For Information (RFI) Process In Construction," Int. J. Constr. Inf. Technol., 7(1), pp. 35-50. 